\title{
A Skype-Buddy Model for Blended Learning
}

\author{
Carmen E. Macharaschwili \\ Linda Skidmore Coggin
}

\begin{abstract}
Online learning in higher education allows distance-education students to complete degree requirements in virtual environments. Universities are challenged with providing quality education experiences for these students and meeting the students' needs for engagement and challenge within a collaborative framework. This study proposes how Voice over Internet Protocol (VoIP) could be used to provide face-to-face participation in a traditional classroom using a unique "Skype-buddy" system. In this project we examined the experiences related to the satisfaction, benefits, challenges, and surprises of each of the participants (Skype buddies, professors, and other students in the class) in two doctoral seminars.
\end{abstract}

\section{A Skype-Buddy Model for Blended Learning}

Online learning is common in higher education, allowing distance-education students to complete degree requirements in virtual environments. Universities are challenged with providing quality education experiences for these students and meeting the students' need for engagement and challenge within a collaborative framework. With the ever-changing landscape of computer-mediated communication tools, this study proposes how Voice over Internet Protocol (VoIP) could be used to provide face-to-face participation in a traditional classroom.

Some educators have responded to this issue with what is termed a blended learning environment. Garrison and Kanuka (2004) define blended learning as "the thoughtful integration of classroom face-to-face learning experiences with online learning experiences" (p. 96). There are many forms of blended learning that include the combination of face-to face (traditional classroom) and asynchronous (text based, Internet) environments. In this project we propose a new concept of blended learning: that of virtual face-to-face with the use of Skype technology in the classroom.

Skype is a form of VoIP/video (Voice Over Internet Protocol with video) software that allows for video and voice calls to be made over the Internet. In addition to voice and video functions, Skype also has a synchronous chat function. This form of software simulates the face-to-face environment of a traditional classroom while still allowing a student to participate at a distance. 
Though various forms of this type of environment have been used, this study is unique in the method of applying a "Skype-buddy" system. The distance student (online) is paired with a proxy student (in the traditional face-to-face classroom) who is responsible for adjusting the camera, volume, and computer to allow for full participation by the distance student. In this project the researchers participated in a Skype-buddy model in two doctoral seminars and examined the experiences related to the satisfaction, benefits, challenges, and surprises of each of the participants.

Our main research questions are:

1. How does using Skype in a blended learning environment shape participants' (distance student and proxy student) engagement in the (online and traditional) classroom?

2. What are the satisfactions, benefits, challenges, and surprises for other students and instructors in a traditional classroom when Skype is used to include a distance student in full class and small group work in the classroom?

\section{Review of the Literature}

A good deal of research has been done on distance education in general. Roblyer and Wiencke (2004) found that the degree of interaction among participants in distance education classes contributes to both student achievement and satisfaction. Our research builds upon this finding. Specifically, we examined a virtual version of blended learning as a means to increase interaction among the distance learner, professor, and classmates.

Garrison \& Cleveland-Innes (2005) examined the effect of interaction and its impact on student satisfaction and found that interaction needs to be structured and systematic for online education. In addition, in order to create a community of inquiry where interaction is meaningful and sustained and ideas are shared, this community must include various forms of interaction to include interaction among content, instructors and students. The various forms of interaction included in this blended learning study include the use of Skype video conferencing, the Skype chat function, an online asynchronous environment through the use of the online course environment, phone calls, and face-to-face conversations among the students, professor and other classmates.

Few studies have reported the use of VoIP to allow virtual participation in a traditional classroom. Samsonov and Harris (2010) conducted a pilot study with three homebound students to determine if Skype technology could be effectively used to allow active participation in the traditional classroom. Skype was successful in providing access, but a limitation was the motivation of the homebound student to use the technology and participate during class time. Another study reported by Newman (2007) looked at using current VoIP technology to add synchronous voice communication to an online course in response to the finding that many students of online courses were dissatisfied with the lack of personal interaction with the instructor. Students were presented with instructional material for the use of the 
Skype application, and instructors were available to students via the VoIP technology. Students were enthusiastic about the Skype application and found it easy to use, but like those in the previous study cited (Samsonov \& Harris, 2010) did not or rarely took advantage of the opportunity to use the VoIP to connect with the instructor.

Our study addresses these limitations by pairing two students. This model extends the paradigm to go beyond the teacher-controlled environment and include the distance learner as a participant in regular classroom activities through the VoIP and the partner student. In the Samsonov and Harris study, the "camera view" was set on the white board used for instruction. In the seminar used for this study, PowerPoint presentations by the instructor and other materials handed out were available online for the distance learner to access during class time. The purpose of this design is to hold students more accountable by being in control of making the connecting call, controlling the camera "view," and communicating through the chat feature during class to enhance the experience. Thus, the students are not only responsible for their own participation, but to each other as well.

The emotional and experiential aspects of learning in blended learning settings were reported by two research studies that inform our work. Blau \& Caspi (2008) examined the differences between audio conferencing (using Skype with an audio-only component) and traditional face-to-face learning. They found that while learning was the same in both groups, the emotional-experiential aspects favored face-to-face communication. Significant differences in favor of face-to-face communication were found in the emotional-experiential aspects of learning: amount of students' attention and interest, learning satisfaction, and enjoyment from the interaction with tutor or peers. Supporting these findings, Ryobe (2009) reported that $100 \%$ of the video chat students' free comments were positive in his study in 2007 and 2008, compared to $90 \%$ of voice chat groups in 2006. Furthermore, it was found that the students involved in the video chats achieved better performance and motivation.

The Skype-Buddy project adds dimension to the notion of an "interaction equation" (Roblyer \& Weincke, 2004, p. 2). An interaction equation is defined as "a created environment in which social and instructional messages are exchanged among entities of a course and in which messages are both carried and influenced by the activities and technology resources" (Roblyer \& Weincke, 2004, p. 5). Our research adds to the "interaction equation" by creating the partnering relationship that provides virtual entrance into the interaction of the traditional classroom through Skype and real time chat to facilitate interaction among participants.

\section{Methods}

\section{Settings and Context}

This research took place in two doctoral seminars offered in a large university in the Midwestern region of the United States. The primary class (blended learning class) offered access to both online and traditional classroom students. The class, Electronic Language and Literacy Learning, consisted of fifteen weekly three-hour 
traditional class meetings for on-campus students. An online component provided access to four distance-education students who attended two to three class meetings for face-to-face presentations and attended the rest of the class sessions in an online forum format. The other seminar, focused on issues in language education, was a face-to-face, on-campus doctoral seminar that met weekly in a traditional classroom environment.

\section{Participants}

The primary participants in this study are two doctoral students (participant researchers) enrolled in both doctoral seminar classes. Author 1, Carmen, participated in the blended learning class as a "distance learner" taking advantage of the online option and commuted 200 miles to participate in the traditional class seminar once a week. Linda, Author 2, is a traditional student who attended both doctoral seminars as a traditional on-campus student. These students acted as Skype buddies during the semester. Other participants are the twenty-three students (19 traditional students and 4 distance students) also enrolled in the same doctoral seminars and two professors that teach the seminars.

\section{Description of Process}

Beginning on the third class meeting of the 15-week semester a "Skype-buddy" partnership was initiated. In the blended learning class, Linda began "Skyping" Carmen into class. Linda brought her personal laptop and external microphone to class, and used Skype software to allow Carmen to listen and participate in class lectures, whole group and small group discussions as a "virtual" student on the computer. During small group discussions, the computer "Carmen" was moved to form the small group meeting. For large group learning, the computer was placed on a table or desk and oriented toward the primary speaker for the class whether it was the professor, a guest speaker, or a student. The screen was adjusted so that the classroom's projected large screen with slides was visible to Carmen via the laptop camera. During each class meeting Carmen and Linda also used the chat feature of Skype to communicate during the Skyped session.

This virtual participation continued for all remaining class periods (12) in the blended learning class except on one occasion when Carmen physically attended the class to give a presentation. With the use of Skype's screen-sharing function, Carmen was even able to present to the class from a distance on two occasions. The laptop with the virtual student was connected to the class projector and displayed for the class during the presentation with the use of the screen share option on the Skype software.

A similar protocol was used in the traditional class to allow Carmen to virtually attend the class. Linda, as the Skype buddy, accessed the traditional class via Skype for Carmen during two additional class meetings. During the traditional seminar class format, Carmen, as a virtual student, had access to both large and small group discussions. 


\section{Data Collection}

How does using Skype in a blended learning environment shape participants' (distance student and proxy student) engagement in the classroom (virtual and traditional)? To address this primary research question, the researcher-participants collected the following data.

\section{Journal Entries}

Skype Buddies kept a journal of field notes during and after each class session when Skype was used. Participants addressed, but were not limited to, recording perceptions of satisfactions, benefits, challenges, and surprises that were encountered with equipment, physical arrangements and any other observations about the learning environment.

\section{Chat Records}

Skype Buddies used the chat feature available through Skype software for additional communication. This chat was used to record perceptions of ease of use, engagement in class activities, and any problems that were encountered with equipment or physical arrangements during the class session using Skype. All chat records generated during class sessions were archived through Skype software.

\section{Classroom Observation and Recording}

Two class meetings were audiorecorded and one of these class small group sessions was transcribed with observational field notes. This recording provided a record of student and instructor interaction with the virtual student in the classroom. These recordings helped to triangulate data from anecdotal and chat records to include another view of specific interactions of participants during class sessions.

Journal entries, chat records, and small group observation and transcription were analyzed and coded using inductive and comparative methods to uncover common themes related to the participants' engagement and learning in the classrooms reflecting satisfactions, benefits, challenges and surprises. Using these methods in two different classrooms strengthens the validity of the data. A qualitative case study to describe the experiences and perspectives of the distance student and traditional student will be used to answer the first research question.

In addition to classroom recordings, interviews and a survey were used to address the second research question to identify satisfactions, benefits, challenges, and surprises for other students and instructors in a traditional classroom when Skype was used to include a distance student in full class and small group work in the classroom.

\section{Interviews}

Semistructured interviews were conducted with the two professors of the seminars, one distance learner from the hybrid learning class, and two traditional students (one from each class where Skype Buddy was in place) after six weeks of using 
Skype in the classroom. Students were selected who had interacted with Carmen as a virtual student in a small group and large group setting. These interviews were analyzed and coded using inductive and comparative methods to find common themes related to the satisfactions, benefits, challenges, and surprises for other students and the instructors in a traditional classroom when Skype was used to include a distance student in the classroom.

\section{Survey}

Students in both classrooms were asked to voluntarily complete an online survey regarding their views of the perceived benefits and challenges related to the use of Skype to include a virtual student in the classroom activities. Survey questions were based on the Classroom Community Scale (Rovai, 2002). This survey was offered online and included twenty-three questions using a 5-point Likert scale with two additional open-ended questions. (Appendix A). This survey was used to determine other class members' views of the benefits and challenges resulting from the use of Skype in the classroom.

\section{Triangulation of data}

A qualitative case study approach is used to describe the experience of Skype Buddies. Comparison of the field notes of Skype Buddies, online chat between buddies during Skype sessions, class session audiorecording, professor and student interviews, and student surveys provided for triangulation of the data. Furthermore, the use of the Skype Buddy system in two separate doctoral seminars allowed for further analysis of the data. Finally, researcher-participants exchanged field notes, independently coded field notes and chat records, and met to compare findings. Definitions were generated to define emerging themes and inter-rater agreement was reached through modification and clarification of category definitions, and some items were discussed and recoded as a result of the inter-rater definition agreements.

\section{Results}

\section{Chat Session}

Chat sessions were coded separately and results yielded similar coding categories by each researcher-participant. Though there were minor differences in how each researcher defined categories, the category topics were similar. For example, Carmen coded certain entries as "emotions" and Linda coded the same or similar entries as "personal." As a result, definitions were established; Table 1 provides definitions, examples, and frequency of categories that resulted through discussion and comparison of samples in the chat sessions. 


\begin{tabular}{|c|c|c|c|c|}
\hline Category & Definition & Count & $\%$ & Examples \\
\hline Technological & $\begin{array}{l}\text { Functioning, adjustment, or } \\
\text { observations regarding the use } \\
\text { and placement of the different } \\
\text { technologies, i.e. computer, } \\
\text { microphone, camera, power } \\
\text { point, internet connection, etc. }\end{array}$ & 115 & 31 & $\begin{array}{l}\text { [10/13/10 4:09:07 PM] } \\
\text { Linda: I made you bigger I } \\
\text { never thought of that!? } \\
\\
\text { [9/15/10 4:12:54 PM] } \\
\text { Carmen: Can you move the } \\
\text { camera more on him? }\end{array}$ \\
\hline Personal & $\begin{array}{l}\text { Personal comments not directly } \\
\text { related to class content like } \\
\text { thoughts or feelings regarding } \\
\text { environment or personal } \\
\text { schedules. }\end{array}$ & 94 & 26 & $\begin{array}{l}\text { [9/15/10 4:12:54 PM] } \\
\text { Carmen: I have to go in } \\
\text { about } 20 \text { minutes if not } \\
\text { sooner--babysitter issues! } \\
\text { My hubby called and can't } \\
\text { take the kids to soccer }\end{array}$ \\
\hline Information & $\begin{array}{l}\text { Data that informs distance } \\
\text { student of what is occurring by } \\
\text { proxy student, includes } \\
\text { questions from distance student } \\
\text { for clarification or comments } \\
\text { that the proxy student believed } \\
\text { would aid distance students in } \\
\text { understanding }\end{array}$ & 112 & 30 & $\begin{array}{l}\text { [9/15/10 4:12:54 PM] } \\
\text { Carmen: I can't hear her at } \\
\text { all } \\
\text { [9/15/10 5:12:58 PM] } \\
\text { Linda: she said keep } \\
\text { traditional literacy }\end{array}$ \\
\hline Participation & $\begin{array}{l}\text { Comments and questions } \\
\text { directly related to in-class } \\
\text { subject matter, comments from } \\
\text { distance students directly to } \\
\text { proxy student, to small groups } \\
\text { in-class, and to whole class or to } \\
\text { professor }\end{array}$ & 28 & 8 & $\begin{array}{l}\text { [9/15/10 5:12:58 PM] } \\
\text { Linda: What are other } \\
\text { interesting points or } \\
\text { questions } \\
\text { [10/4/10 4:23:12 PM] } \\
\text { Carmen: teacher as learner } \\
\text { rather than all-out authority } \\
\text { figure }\end{array}$ \\
\hline Project & $\begin{array}{l}\text { Discussion between the distance } \\
\text { and proxy student directly } \\
\text { related to the research project, } \\
\text { not tied to technology or class } \\
\text { but rather to the research } \\
\text { process }\end{array}$ & 21 & 6 & $\begin{array}{l}\text { [9/27/10 5:38:18 PM] } \\
\text { Carmen: approach to } \\
\text { collecting the data--yes! I } \\
\text { would be nodding in class! } \\
\text { [9/27/10 5:38:28 PM] } \\
\text { Linda: think of all the } \\
\text { messaging on this Skype } \\
\text { [9/27/10 5:38:47 PM] } \\
\text { Carmen: I KNOW...there is } \\
\text { another aspect to our study } \\
\text { to make it unique! }\end{array}$ \\
\hline
\end{tabular}

Table 1. Examples and Definitions of Chat Session Coding

Differences in the results for the traditional seminar class, where Skype was used in only two classes, were noted related to visual and audio constraints. The classroom configuration made it more difficult to set up the personal computer so that the distance student could see and hear the whole class presentations. As a result, the information category was significantly increased because the proxy student felt the need to narrate the class via the chat function because she perceived that the distance student was not able to see and hear what was going on in the 
classroom. The results for this category without the traditional class would have been fourteen percent if the second class had not been included in chat coding analysis.

\begin{tabular}{|c|c|c|c|c|c|}
\hline \multirow[b]{2}{*}{ Category } & \multirow[b]{2}{*}{ Definition } & \multicolumn{2}{|c|}{ Distance Student } & \multicolumn{2}{|c|}{ Proxy Student } \\
\hline & & Field Note & Explanation & Field Note & Explanation \\
\hline Satisfaction & $\begin{array}{l}\text {-personal } \\
\text { satisfaction } \\
\text {-closely tied } \\
\text { to emotion } \\
\text {-how the } \\
\text { participant } \\
\text { feels about } \\
\text { the } \\
\text { experience. } \\
\text { Example: } \\
\text { relationship } \\
\text { building and } \\
\text { personal } \\
\text { connection. }\end{array}$ & $\begin{array}{l}\text { YAY I felt like } \\
\text { I was } \\
\text { contributing } \\
\text { to the class! }\end{array}$ & $\begin{array}{l}\text { Acknowledged } \\
\text { as class } \\
\text { participant, } \\
\text { able to gain } \\
\text { and } \\
\text { contribute }\end{array}$ & $\begin{array}{l}\text { "Do you carry } \\
\text { her around } \\
\text { everywhere?" }\end{array}$ & $\begin{array}{l}\text { Another classmate } \\
\text { is perceiving the } \\
\text { "buddies" as } \\
\text { inseparable-an } \\
\text { interesting } \\
\text { perception from } \\
\text { which the proxy } \\
\text { student gained a } \\
\text { sense of } \\
\text { satisfaction }\end{array}$ \\
\hline Benefits & $\begin{array}{l}\text {-closely tied } \\
\text { to learning or } \\
\text { increase in } \\
\text { knowledge } \\
\text { Example: } \\
\text { contribution } \\
\text { to learning } \\
\text { and to class. }\end{array}$ & $\begin{array}{l}\text { I got to hear } \\
\text { [the } \\
\text { professor's] } \\
\text { anecdotal } \\
\text { input from } \\
\text { his } \\
\text { experience } \\
\text { and } \\
\text { knowledge-- } \\
\text { like the } \\
\text { survey done } \\
\text { in Canada } \\
\text { for example }\end{array}$ & $\begin{array}{l}\text { Information } \\
\text { gained from } \\
\text { Skype that I } \\
\text { couldn't get in } \\
\text { a purely } \\
\text { online } \\
\text { environment. }\end{array}$ & $\begin{array}{l}\text { I don't have } \\
\text { time for my } \\
\text { mind to wander } \\
\text { because I don't } \\
\text { just think about } \\
\text { how I am } \\
\text { receiving } \\
\text { information. I } \\
\text { think how } \\
\text { Carmen might } \\
\text { be 'seeing'. }\end{array}$ & $\begin{array}{l}\text { An expression of } \\
\text { heightened } \\
\text { awareness of } \\
\text { what is taking } \\
\text { place in class as } \\
\text { attributed to the } \\
\text { responsibility to } \\
\text { the distance } \\
\text { student. }\end{array}$ \\
\hline Challenges & $\begin{array}{l}\text {-closely tied } \\
\text { to the actual } \\
\text { use of the } \\
\text { hardware } \\
\text { and software. } \\
\text { Example: } \\
\text { equipment } \\
\text { and } \\
\text { connection } \\
\text { issues and } \\
\text { distractions } \\
\text { related to } \\
\text { such issues. }\end{array}$ & $\begin{array}{l}\text { Dog } \\
\text { barking- } \\
\text { can't hear }\end{array}$ & $\begin{array}{l}\text { Distractions } \\
\text { that come } \\
\text { with being at } \\
\text { home instead } \\
\text { of the real } \\
\text { classroom }\end{array}$ & $\begin{array}{l}\text { "It is still } \\
\text { difficult to chat, } \\
\text { I wish the } \\
\text { camera was on } \\
\text { the back of the } \\
\text { laptop!!!" }\end{array}$ & $\begin{array}{l}\text { Expression of } \\
\text { frustrations due } \\
\text { to set-up of } \\
\text { technology }\end{array}$ \\
\hline Surprises & $\begin{array}{l}\text {-unexpected } \\
\text { results of the } \\
\text { use of the } \\
\text { VoIP } \\
\text { technology }\end{array}$ & $\begin{array}{l}\text { Without } \\
\text { Linda, I } \\
\text { didn't feel as } \\
\text { if I was } \\
\text { interacting. }\end{array}$ & $\begin{array}{l}\text { Emotional } \\
\text { connection }\end{array}$ & $\begin{array}{l}\text { "It was really } \\
\text { just like } \\
\text { another person } \\
\text { being there }\end{array}$ & $\begin{array}{l}\text { Reference to a } \\
\text { small group } \\
\text { discussion in } \\
\text { which distance } \\
\text { student }\end{array}$ \\
\hline
\end{tabular}




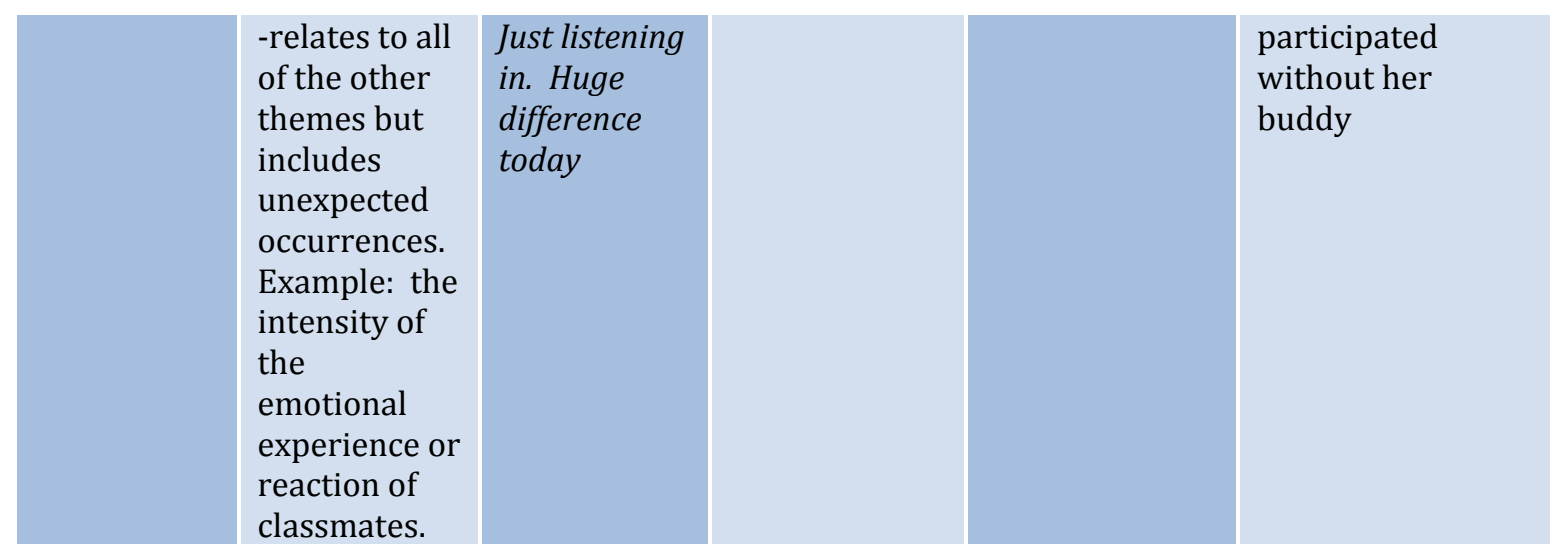

Table 2 Examples of and Definitions of Field Note Coding

From the chat results, it is clear that most of the chat function was used to resolve technical difficulties and share basic information to clarify what was happening in the classroom (approximately 60\% for both classes, approximately $45 \%$ for blended learning class). Personal comments that were not related to the class were the second most frequent chat category (30\%). Actual participation and discussion of the researcher participant was minimal (only 14\%). It is necessary to look at this data in conjunction with the field notes in order to analyze the "whole picture."

The field notes corroborate the data derived from the analysis of the chat notes. Both the distance and the proxy student benefited and were surprised by the level of personal connection that took place between them and with other class participants. This opportunity for personal connection is evidenced by the fact that $30 \%$ of the chat comments were of a personal nature and this personal connection was also noted in the field notes.

The research-participants noted their biggest challenges were technical issues. Thirty-one percent of the chat comments were about technical adjustments; in fact, 16/22 chat notes coded as challenges in the first 5 class periods were about physical placement of equipment. These technological issues did not interfere with the personal connection. The day that the distance student felt most "distant" was the day that there were no technological issues, but rather, little interaction with the proxy student.

The virtual face-to-face connection and chat conversation permitted through the software was an important piece in the distance student's perception of participation. The adjustment of hardware and placement of the computer were directly related to participation. Throughout the field notes there were comments about classmates touching the mouse pad to make sure the computer didn't sleep, making sure the microphone was placed correctly, and moving the Skype window so that the distance student could be seen. Through these actions, many people in the class were able to interact with the Skype buddies. Table 3 provides examples that show how the combination of participation opportunities and challenging 
technological issues produced surprising benefits for both the proxy and the distance student.

\begin{tabular}{|c|c|c|}
\hline Category & Example & Explanation \\
\hline Personal & $\begin{array}{l}\text { (Linda 10/27/10) Carmen's daughter was } \\
\text { "entertaining" Tara's daughter who was in class by } \\
\text { holding up a phone and making noises- it was } \\
\text { really funny. It was also nice to actually see her } \\
\text { daughter on Skype. } \\
\text { (Linda10/4/10) People were saying "hi" to Carmen } \\
\text { when came in. } \\
\text { (Carmen 11/3/10) Interesting that after we talked } \\
\text { about how attentive Linda is last week-I did not } \\
\text { feel that way today. Weird feeling, almost like she } \\
\text { was mad or something. Without Linda, I didn't feel } \\
\text { as if I was interacting. Just listening in. Huge } \\
\text { difference today. No [technological] glitches } \\
\text { whatsoever today though }\end{array}$ & $\begin{array}{l}\text { A personal connection } \\
\text { was made among } \\
\text { classmates in an informal } \\
\text { discussion that had } \\
\text { nothing to do with class } \\
\text { Acknowledgement of } \\
\text { distance student as part } \\
\text { of the classroom } \\
\text { community } \\
\text { Evidence of the } \\
\text { importance of personal } \\
\text { connection even when the } \\
\text { technology was working } \\
\text { correctly. }\end{array}$ \\
\hline Technological & $\begin{array}{l}\text { (Carmen 9/22/10) Couldn't hear the other group } \\
\text { until they moved the mic and then confused me } \\
\text { when I couldn't see for a minute. } \\
\text { (Linda 10/27/10) I thought this would be a better } \\
\text { place for the microphone because Carmen has said } \\
\text { she can't hear these girls }\end{array}$ & $\begin{array}{l}\text { These examples give } \\
\text { evidence of the } \\
\text { frustration caused by } \\
\text { technical issues and the } \\
\text { adjustments necessary to } \\
\text { improve the quality of the } \\
\text { interaction }\end{array}$ \\
\hline Information & $\begin{array}{l}\text { [10/6/10 4:49:58 PM] Carmen: My questions: how } \\
\text { do I access the climate change CWR? How will } \\
\text { teachers access the new system? Will you charge? } \\
\text { Free? How is it marketed? } \\
\text { [10/6/10 4:49:59 PM] Linda: do you want me to } \\
\text { ask } \\
\text { [10/6/10 4:50:14 PM] Carmen: yes please or let } \\
\text { him know i have a question }\end{array}$ & $\begin{array}{l}\text { These are examples of } \\
\text { how the use of the use of } \\
\text { the proxy student acting } \\
\text { as an "interpreter" and } \\
\text { the chat function being } \\
\text { used to communicate } \\
\text { basic class information. }\end{array}$ \\
\hline $\begin{array}{l}\text { Project } \\
\text { Participation }\end{array}$ & $\begin{array}{l}\text { (Carmen 10/13/10) I was able to participate in full } \\
\text { group discussion, with [Professor] calling on me. } \\
\text { (Linda 9/22/10) It was really just like another } \\
\text { person being there (ref. to small group discussion) } \\
\text { (Linda 9/22/10) Carmen presented to class for her } \\
\text { group and I could feel everyone closing in- I } \\
\text { thought it was good- they were including the cyber } \\
\text { person in the group. }\end{array}$ & $\begin{array}{l}\text { The expressions of both } \\
\text { students are those of } \\
\text { satisfaction in making a } \\
\text { virtual situation "feel" } \\
\text { real. The recognition of } \\
\text { the distance learner as } \\
\text { being a person } \\
\text { participating in a real- } \\
\text { time discussion is } \\
\text { evident. }\end{array}$ \\
\hline
\end{tabular}

Table 3. Participation Opportunities and Technological Issues 
As shown in the examples above, the researcher-participants perceived that despite frustrations, more learning was taking place as a result of the opportunities afforded by the Skype technology. For the distance student this is obvious. The faceto-face interaction provided through the software gave opportunities for immediate feedback that would not be possible in an online session. Surprisingly, the benefits extended to the proxy student as well. The responsibility for monitoring the distance student's participation forced the proxy student to attend to the class in a different way. These perceived benefits are evident in the chat and field notes of the researcher participants. For example, "I do think I change the way I listen then because I'm not thinking about can she hear or see, are there cues she is missing by not being here? I am listening more for content. When I'm on my own, my mind wanders to other things. That doesn't happen when I am responsible for Skype." (Linda, field notes October 4, 2010). "It helps me to immediately be able to talk [chat] to you." (Carmen chat notes, September 22, 2010).

Interviews with professors and students and anecdotal evidence from chat messages and personal field notes yielded several themes related to other students' and instructors' satisfaction, benefits, challenges, and surprises when the SkypeBuddy system was used in the classrooms. Three main themes emerged in the analysis of this data:

- Access

- Connections/Relationship

- Distraction (as related to use of VoIP Technology in the classroom by Skype buddies)

The primary theme salient in all data sources was access. Three kinds of access can be identified in the interview transcripts and notes; 1) access to graduate work, 2) access to traditional "class" by online participation, and 3) access to class as a "virtual" student through the use of technology. Online classes and our study of a "virtual student" provided access to graduate work for students who may have limited access to a traditional onsite class. Professor A said, "Our graduate program, especially for doctoral students, hasn't been able to employ everybody. So we've got lots more people, in fact about a quarter of our class, as a matter of fact, who have to be full time employees someplace else" (Professor A interview, November 2010). Each student interviewed expressed that Carmen was able to get the "full benefit of class without physically having to sit in class" and "still learn" (M interview, November 2010).

Access in this study was also interpreted as allowing flexibility. One of the professors commented that technology allows students to be in more than one place at a time- "Someone who's traveling or someone who cannot be there [in class] for a particular reason but who could be there in a computer just for the class" (Professor B interview, November 2010)—and identified this as an alternative way to attend class. This was the case in the traditional doctoral seminar that Carmen attended on campus but Skype allowed her to still "attend" class when she had other commitments that prevented her from making the long drive to campus. 
The Skype Buddy distance student, by virtual participation, has access to the same knowledge and opportunities afforded onsite students in the traditional classroom community. Carmen was aware that she had access to class presentations by other students and frequent guest speakers that were not available to students attending only online. In field notes she commented: "How will the distance students receive access to these presentations? Another huge loss? "(Carmen's field notes, October 6, 2010). Another online student, noted that

When I look at the way you [Linda] and Carmen have created this environment for Carmen and although she's had to leave early she still gets the benefit of the conversation that happens in that face-to-face class and I'm not getting that benefit. That's a choice that I made, I chose to take this class [as an online student] but if I had the opportunity to Skype in I think that that conversation that happens inside those four walls would be really important and enlighten me quite a bit. (Student M interview, November 2010)

Carmen's participation in small groups was another way this partnership allowed access to class sharing, but it was noted by another student that she had "trouble knowing how to relate to a virtual presence" (student S interview, November, 2010). In the transcription of a small group class interaction that involved the virtual student, an observation was made (observation notes and transcription of small group interaction on September 29, 2010) that one group member was looking at Linda and pointing to the computer where Carmen's image was, and said, "I can't hear that" (pointing to the computer screen and looking at Linda). It is interesting he says "that" instead of referring to Carmen as a person. The same incident was referenced by Carmen in her field notes, "student (name) doesn't seem to be catching what I'm saying" (Carmen field notes, September 29, 2010). Both of these traditional students later commented in interviews that "after it (Carmen "Skyped" into class) happened a couple of times, however, it felt like she was really in the classroom and seemed very natural" (student S interview, November, 2010).

One professor indicated that the virtual participation allowed by Skype somewhat addressed concerns he had about online classes in higher education. He could "see" the virtual student participating in small group discussion and hear her spontaneous comments and her "think[ing] on her feet," which enhanced his view of her. A distance student, who also teaches an online class, said "[my] class is one where I think we need to have some conversations among us rather than just us having the conversation in the forum because so much is lost in just textual language. So yeah, I think that Skype would help a lot with that" (student M interview, November 2010). A traditional student who is in both classes noted, "we can listen to the participant's voice and we can share his or her opinion" (student C interview, November 2010). These are benefits for all students and instructors.

The second theme extends the idea of the benefits of this community to allow for connections with others as a result of technology. In an interview, Professor A 
proposed the importance of connecting with others who are doing similar work. He viewed technology as a means for students to connect with each other electronically and also with students being able to connect with doctoral committees through technology. Technology opens a wider door for access and participation by a more diverse group of people.

There was also evidence that the presence of a "virtual student" through VoIP technology shaped the sense of community in the classroom. This theme is woven in all of the data collection. Professor B said:

For me it became a very, not to sound romanticizing, (kind of laughing) but it came like a very communal thing. Through your computer you can come, you know, can I be in your computer and can we share? (She was saying these like she was pretending to be the person asking these questions to another). So you know it worked out really well I think and I think everybody was like giving their best try to include Carmen in their conversation. So I thought that was very nice. (Professor B interview, November 2010)

In field notes we noted when other students were "helping with the microphone, moving it around when other people were talking" (Linda field notes, September 29, 2010). When small groups met and the Skype Buddy was not in the group, the other students took care of "virtual Carmen." In one small group time, "I (Linda) noticed a very shy girl (I don't think I've ever heard her talk in class) was moving the computer so Carmen could see and this happened more than once" (Linda field notes, September 22, 2010). The first time Carmen informally presented her small group's discussion it was noted in field notes that "Carmen presented to class for her group and I could feel everyone closing in-I thought it was goodthey were including the cyber person in the group" (Linda field notes, September 22, 2010).

Other students in interviews also noted personal connections. A student in the traditional class that Carmen physically attended for most of the meetings stated, "I don't know if she would have felt like such a part of our community if we had only known her in a virtual way" (student S interview, November, 2010). But students in the class that Carmen attended 12/15 of the class meetings as a virtual student felt, "that's why Skype is impressive. If I could see other people I could be more motivated... I think seeing others seems to be important actually" (student C interview, November, 2010). A student who participates in class as an online student (and has attended 2-3 classes to give presentations) said she "felt very disconnected and I think Skype could have helped with that" (student M interview, November 2010).

The idea of problems and distractions created by the VoIP technology use was also a theme in interviews, chat, and notes. Professor B compares the virtual student to a second language learner in the classroom and some of the distractions as "translating" what is going on in the room. The technology as "an irritant and annoyance" when it doesn't work was considered "no different than other kinds of 
distractions like somebody in the hallway" (Professor A interview, November 2010). While Professor B lauded the "improvised nature" of what we were doing, she also mentions several times the need for more technical support and procedures for further implementation of the concept of using VoIP in the traditional classroom (Professor B interview, 2010).

Distraction was often related to audio. The distraction noted by a student in the traditional class related to being able to hear Carmen. She noted, "with a more developed sound system to accommodate the Skyping student, we could feel like the virtual student was really sitting in our class" (student S interview, November 2010). The professors voiced the same concern at times and two of those times were related to the buddy's "human error" - the computer sound was muted (Linda field notes, 11/3/10). This problem was alleviated during presentations when the "virtual student" laptop was connected to the classroom audio system.

The problems and distractions related to technology are no different than other "distractions" in a typical classroom. Seventy-five percent of classmates who completed the online survey about our use of Skype disagreed (4) and strongly disagreed (8) that the use of Skype was a distraction in the classroom. Considering the limitations and possible distractions caused by the technology, "the positives outweigh the negatives by far" (Professor A interview, November 2010). He sums up his feeling on these by saying, "I like the richness of reality intruding".

\section{Discussion}

In a Skype-Buddy Model for Blended Learning, researcher-participants add to the growing body of knowledge surrounding blended learning environments. This study confirms the research done by Roblyer \& Wienke (2004), Garrison \& ClevelandInnes (2005), and Blau \& Caspi (2008) that the degree of interaction provided to a student in a distance-learning environment contributes to student achievement and satisfaction. Both researcher-participants found that the Skype-Buddy system confirmed the benefit of face-to-face communication, even virtually, and contributed to the emotional-experiential aspects of learning: amount of students' attention and interest, learning satisfaction, and enjoyment from the interaction with tutor or peers (Blau \& Caspi, 2008).

The Skype-Buddy partnership changed class engagement for both participants. The proxy student noted a change in class participation in her field notes. "That is when I realized how I notice what is going on in the class in a different way. I don't have as much time for my mind to wander" (Linda field notes, September 27, 2010). The distance student made similar comments that despite the challenges posed by the use of the technology, learning satisfaction was evident. "I'm noticing that even with all of this mess today (referring to distractions at home), I'm probably still getting a lot more out of this than if I were online. ...I can't imagine how those who cannot participate in class are getting half of what I'm getting right now at this moment" (Carmen field notes, September 27, 2010). This fact is further evidenced in the interview with the distance student that was not able to participate in the Skype Buddy model. 
An important outcome of this study is the protocol that was developed to use this technology and the "buddy" design (Appendix B). Another essential aspect to this design is the importance of selecting participant "buddies" and the motivation and amenability of the students and professors involved in the classroom. The protocol outlines the steps for implementing the Skype Buddy design and is a beginning step toward successful implementation. According to Curtis \& Lawson (2001), Martyn (2003), and many others (Bonk \& Graham, 2006; Zhao et al. 2005; Means et al. 2009) the design and implementation of a blended learning environment is essential to success.

Samsonov \& Harris (2010) and Newman (2007) observed that student motivation and student interaction with the professor were also essential factors. Our study confirmed these observations and allows for these interactions in the suggested protocol. Statements from the chat and field notes confirm the responsibility that the proxy student must demonstrate to ensure the opportunity for learning and satisfaction of the distance student.

I was trying to get [Professor A's] attention by waving and then I had to shout out and apologize that I couldn't get their attention and Linda apologized-interesting that she felt responsible, but I didn't even try to "chat" or get her attention because I didn't want to disturb her and have her turn the computer around. It seems we are hyper aware of each other-she feels responsible for my learning (she's said this). (Carmen field notes September 15, 2010)

It seems that even with the challenges involved in conducting a blended learning experience with the VoIP buddy approach, all participants were open to the model and believed that the benefits outweighed the challenges. The importance of this benefit is illustrated by Professor A's comment outlining some of these benefits.

The central thing in most of the work I do has to do with access, has to do with giving people access to knowledge, access to information, access to new opportunities and I think it opens up a wider door for access, for both the kinds of people who can participate in graduate work and for them to be able to have access to what's going on here (referring to the physical university setting) and that's, that's a good. It's an unqualified good. And any efforts to keep that from happening I couldn't see that they would be protecting anything and they would be detrimental. (Professor A interview, November 2010)

Finally, the enjoyment gained from interaction among participants was evidenced in the informal interactions that occurred. Conversations between the "virtual" classmate and onsite class members about favorite books or family interactions during class "breaks" were frequent and allowed a personal connection to occur among students outside of the Skype-Buddy relationship. Most guest speakers stopped to speak to the Skype Buddies after their presentations, perhaps out of sheer curiosity, but again, an opportunity for informal personal interaction 
was achieved. This was further evidenced by survey results in which all participants were asked if they would be willing to participate in a class in a Skype-Buddy situation. The majority agreed that they would be willing to try the model (81\%). In fact, this was evidenced weeks after the conclusion of this study when the researchers continued the practice in the next semester, along with three more "Skype Buddy" teams within the class. Furthermore, through informal conversations, researchers learned that several other classes in the program are using the Skype Buddy Protocol. It is clear that the means for further investigation of this tool is available.

\section{Limitations}

Though clearly this study proved successful for participants, it is limited by the fact that it was a first-time exploratory study conducted by a very small group. Furthermore, the main body of evidence comes from the researcher-participants themselves, who are clearly biased in favor of the novelty of this idea. The professor of the class in which most Skyping took place had the idea to allow for the distance students to participate this way, so this class was particularly supportive of the experiment. In order to confirm the findings of this study, it is essential that future research be conducted using this approach to blended learning.

\section{Implications for Future Research}

For further research, the protocol developed as a result of this study (Appendix B) should be tested and measured. More research is needed on the "fractured space" (Lankshear \& Knoble, 2007) created by having a virtual student in class. Implications for harnessing the energy that the digital generation puts into the use of tools such as VoIP technology calls for this study to be replicated in larger and more diverse populations.

This study utilized the participatory and collaborative nature of new technologies in a "fractured space" (distinctively new cyberspace that coexists with physical space). Lankshear \& Knoble (2007) refer to this social phenomenon as "fracturing of space" that is accompanied by a new mindset. As illustrated by this study, VoIP provided another way of attending class. This coexistence of a traditional and virtual student in the traditional space of an on-campus classroom is possible. More research is needed to determine if this new way of participating in education is indeed a new way of accessing knowledge that is not only enhanced but transformed by interactive technology and empowered learners.

\section{Conclusion}

Will future students (the digital generation) embrace this model of a virtual face-toface student and "buddy" with the use of VoIP technology in the classroom as another multitasking, fractured space, social reality? Is it possible that it might even enable teachers and students to navigate "fractured space" in a beneficial way? Instead of a distraction for their students, can teachers engage the digital learner by forcing them to be responsible to their virtual peer? It is unknown whether offering 
flexibility for the virtual student and a different form of class participation for the proxy student is a new way of providing flexible access to knowledge, more rigorous intellectual participation, and a satisfying social learning component as a different "ethos" (Lankshear \& Knoble, 2007) that allows a new view of distance learning.

\section{References}

Blau, I., \& Caspi, A. (2008). Do media richness and visual anonymity influence learning? A comparative study using SkypeTM. In Y. Eshet, A. Caspi \& N. Geri (Eds.), Proceedings of the Chais Conference on Instructional Technologies Research 2008: Learning in the technological era (pp. 18-25). Ra'anana, Israel: Open University of Israel. Retrieved from http://telempub.openu.ac.il/users/chais/2008/noon/4 2.pdf

Bonk, C., \& Graham, C. (Eds.). (2006). Handbook of blended learning environments. San Francisco: Pfeiffer.

Curtis, D. D., \& Lawson, M. J. (2001). Exploring collaborative online learning. Journal of Asynchronous Learning Networks, 5(1), 21-34.

Garrison, D. R., \& Cleveland-Innes, M. (2005). Facilitating cognitive presence in online learning: Interaction is not enough. The American Journal of Distance Learning, 19(30), 133-148.

Garrison, D. R., \& Kanuka, H. (2004). Blended learning: Uncovering its transformative potential in higher education. Internet and Higher Education, 7, 95-105.

Lankshear, C., \& Knobel, M. (2007). Sampling 'the new' in new literacies. In M. Knobel \& C. Lankshear (Eds.), The new literacies sampler (pp. 1-24). New York: Peter Lang.

Martyn, M. (2003). The hybrid online model: Good practice. Educause Quarterly, 26(1),18-23.

Means, B., Toyama, Y., Murphy, R., Bakia, M., \& Jones, K. (2009). Evaluation of evidence-based practices in online learning: A meta-analysis and review of online learning studies. US Department of Education, Office of Planning, Evaluation, and Policy Development, Policy and Program Studies Service Center for Technology in Learning. Retrieved from www.ed.gov/about/offices/list/opepd/ppss/reports.html

Newman, J. (2007). Using VoIP technology for online course in higher education. In R. Carlsen et al. (Eds.), Proceedings of Society for Information Technology \& Teacher Education International Conference (pp. 444-447). Chesapeake, VA: AACE.

Roblyer, M. D., \& Wiencke, W. R. (2004). Exploring the interaction equation: Validating a rubric to assess and encourage interaction in distance courses. The Journal of Asynchronous Learning Networks, 8(4), 25-37. 
Rovai, A. P. (2002). Development of an instrument to measure classroom community. Internet and Higher Education, 5(3), 197 - 211.

Ryobe, I. (2009). The effects of Skype-based video chats with volunteer Filipino English teachers (II): Discovering the superiority of video chat. Kyoto: Kyoto Sangyo University, Center for General Education.

Samsonov, P., \& Harris, S. (2010). Leading a horse to water: Connecting home-bound students to their classrooms using skype technology. Society for Information Technology \& Teacher Education International Conference Annual (pp. 34743479). San Antonio: Association for Advancement of Computing in Education.

Zhao, Y., Lei, J., Lai, B., \& Tan, H. (2005). What makes the difference? A practical analysis of research on the effectiveness of distance education. Teachers College Record, 107, 1836-1884.

\section{Appendix A}

Please answer the questions based on Classroom Community Scale (Rovai 2002). Answer Strongly Agree, Agree, Neutral, Disagree or Strongly Disagree on the drop down menu. Do not spend too much time on any one statement, but give the response that seems to describe how you feel. Please respond to all items. If you neither agree nor disagree with a statement or are uncertain, or if the statement doesn't apply to you, please mark Neutral.

1. I feel that students in this course care about each other.

2. I feel that I am encouraged to ask questions.

3. I feel connected to others in this course.

4. I feel that it is hard to get help when I have a question.

5. I do not feel a spirit of community.

6. I feel that I receive timely feedback.

7. I feel that this course is like a family.

8. I feel uneasy exposing gaps in my understanding.

9. I feel isolated in this course.

10. I feel reluctant to speak openly.

11. I trust others in this course.

12. I trust others in this course.

13. I feel that this course results in only modest learning.

14. I feel that I can rely on others in this course.

15. I feel that other students do not help me learn.

16. I feel that other students do not help me learn.

17. I feel that I am given ample opportunities to learn.

18. I feel uncertain about others in this course.

19. I feel uncertain about others in this course.

20. I feel that my educational needs are not being met.

21. I feel confident that others will support me.

22. I feel that this course does not promote a desire to learn.

23. How frequently do you use Skype?

24. Skype in the classroom was distracting to the students in the classroom.

25. Please add any other comments to aid us in researching the use of Skype in the classroom.

26. Please record some comments about your experiences with Skype in the classroom. 


\section{Appendix B-Buddy Protocol}

Hardware:

- Laptop computer

- Internet connection

- Web camera

- External microphone

- Modem/Wireless or High Speed Internet Connection

- External Speakers (Optional)

VoIP Software: (Skype, Google Video, etc.)

Use:

- Set up VoIP accounts, exchange user names and permissions

- Test how make and receive calls, activate video feature

- Access to chat function

- Use of File Share

- Make sure the Skype-Buddies use the same software and updated versions

Optimal Classroom Configuration:

- Table for laptop set up, near electrical outlet

- U shape or seating arrangement that allows for close proximity for whole class discussion

- Clear view to presenter/slides if applicable

- Location of microphone can be adjusted for group

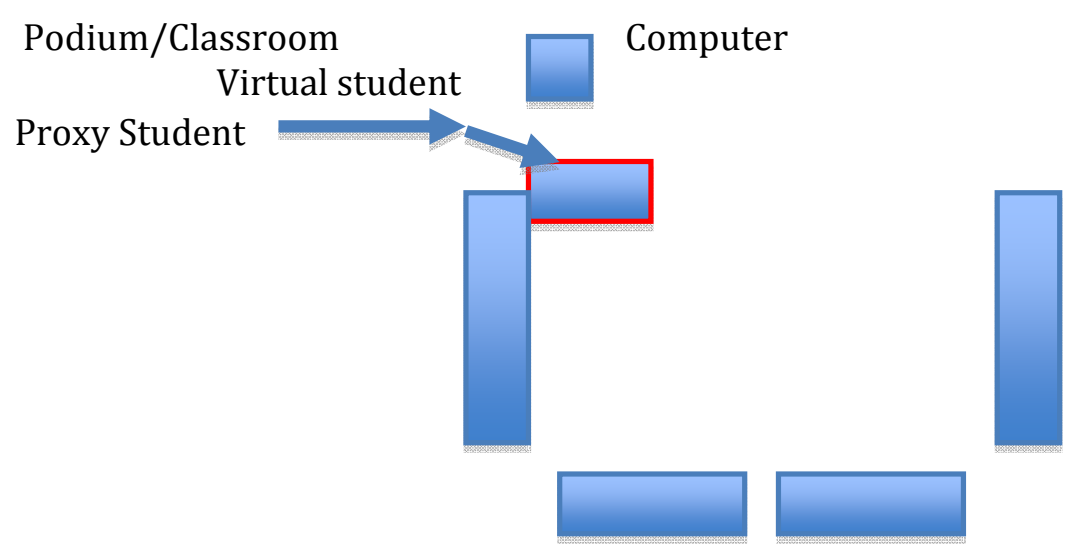

Proxy student might sit with virtual student positioned so that proxy student can "see" virtual student and notice chat box. If an external web camera is used experiment with placement on "back" of laptop screen so the proxy student can still use computer screen facing proxy student. Microphone can be placed on table near virtual student (whole class) or within small group for discussion.

Proxy Student:

1. Arrive in class in time to set up beforehand- choose seat that allows for full view of presentation area.

2. Plug computer into outlet- VoIP takes energy!

3. Plug in external microphone and place it where needed. (For example, close to "soft spoken" classmates or near presentation area if teacher or student presenter).

4. Best to sit so that computer screen can be viewed from "the side" so camera can see class or presentation area and you can see the chat. 
5. Call distance student when ready-- call can be muted so that it doesn't "ring" if class has started. Just don't forget to change mute so virtual student can be heard. Be sure to signal to distance student and check chat function to be sure that everything is working properly.

6. Size of "virtual student" can be enlarged by dragging lower right corner or choosing view full screen.

7. Chat feature of Skype can be accessed and is useful to monitor needed adjustments without disturbing class.

8. Laptop can be moved to accommodate small group interactions. The Skype buddies don't have to be in the same group! Other students will help.

Distance Student:

1. Be ready to answer call when distance student calls.

2. Confirm that VoIP is working properly, signal to classmate to indicate that it is okay or use chat function to indicate if you cannot see or hear well.

3. Use the mute to avoid feedback or background noise-Turn off mute when you would like to speak.

4. Be an active participant-be proactive in communicating with others. Use a combination of chat and voice to indicate where to turn the camera, if you want to contribute to whole or small group discussion, if you can't see, let your "buddy" know. Clear communication is the only way your buddy can help.

Instructor:

1. Announce to class that "virtual" student will participate in class-awareness is key and will minimize distraction.

2. Make handouts and power points and links (YouTube, etc.) used in class available in resources on OnCourse for virtual student to access during class. Ask students who are presenting to do so as well.

3. Speak to virtual student during class, elicit their responses when appropriate.

4. Ensure optimum classroom configuration for Skype buddy when possible.

Other Students: Other traditional classroom students should be invited to interact with the Skype buddies by both engaging the virtual student in discussion, and by helping the proxy student with hardware and software adjustments as needed. 